ARTICLE

Received 23 Jul 2014 | Accepted 18 Aug 2014 | Published 25 Sep $2014 \quad$ DOl: 10.1038/ncomms6027

\title{
Benzene construction via organocatalytic formal $[3+3]$ cycloaddition reaction
}

Tingshun Zhu', Pengcheng Zheng ${ }^{1,2}$, Chengli Mou ${ }^{1,2}$, Song Yang ${ }^{2}$, Bao-An Song ${ }^{2} \&$ Yonggui Robin Chi ${ }^{1,2}$

The benzene unit, in its substituted forms, is a most common scaffold in natural products, bioactive molecules and polymer materials. Nearly $80 \%$ of the 200 best selling small molecule drugs contain at least one benzene moiety. Not surprisingly, the synthesis of substituted benzenes receives constant attentions. At present, the dominant methods use pre-existing benzene framework to install substituents by using conventional functional group manipulations or transition metal-catalyzed carbon-hydrogen bond activations. These otherwise impressive approaches require multiple synthetic steps and are ineffective from both economic and environmental perspectives. Here we report an efficient method for the synthesis of substituted benzene molecules. Instead of relying on pre-existing aromatic rings, here we construct the benzene core through a carbene-catalyzed formal [3+3] reaction. Given the simplicity and high efficiency, we expect this strategy to be of wide use especially for large scale preparation of biomedicals and functional materials.

\footnotetext{
${ }^{1}$ Division of Chemistry \& Biological Chemistry, School of Physical \& Mathematical Sciences, Nanyang Technological University, Singapore 637371, Singapore.

${ }^{2}$ Laboratory Breeding Base of Green Pesticide and Agricultural Bioengineering, Key Laboratory of Green Pesticide and Agricultural Bioengineering, Ministry of Education, Guizhou University, Guiyang 550025, China. Correspondence and requests for materials should be addressed to B.-A.S.

(email: basong@gzu.edu.cn) or to Y.R.C. (email: robinchi@ntu.edu.sg).
} 
M

ulti-substituted benzenes are widely present in natural products. In industry, these benzene frameworks are nearly unavoidable in preparing most of today's biomedicals, fine chemicals and polymer materials. The functions of the benzene-containing molecules are determined by the identity and substitution patterns of the substituents installed on the benzene unit. Exemplified in Fig. 1a are one natural product (salvadorin) ${ }^{1}$ and two synthetic bioactive molecules ${ }^{2,3}$ containing a benzene core bearing four substituents. Most synthetic methods in synthesizing such multi-substituted aromatics start with preexisting benzene unit by replacing hydrogen with other functional groups. The classic approach relies on stepwise electrophilic substitution (such as Friedel-Crafts reaction) or electrophilic halogenation and successive transition metal-catalyzed couplings. However, regio-selectivity and chemo-selectivity normally require rather tedious functional group (including protecting group) manipulations. For example, the classic synthesis of a 2,4,6trisubstituted benzoate needs the introduction of a temporary amine group to ensure selectivities in a key bromination reaction step $^{4}$, and the overall synthesis requires over eight steps (Fig. 1b). Another approach for access to substituted benzenes is based on transition metal-catalyzed direct $\mathrm{C}-\mathrm{H}$ activations ${ }^{5-8}$. While providing impressive shortcuts for benzene substitutions, this $\mathrm{C}-\mathrm{H}$ activation method has its own limitations. For example, the presence of directing groups (for coordination with the metal catalyst) is often necessary and the instruction of multiple substituents is difficult (in part due to steric congestion). In a different direction for substituted benzene synthesis, the benzene core is newly formed. Representative methods include transition metal-catalyzed $[2+2+2]$ or $[4+2]$ reactions such as acetylene trimerizations developed by Reppe et al. ${ }^{9-11}$ In this cycloaddition approach, partial or complete intramolecular reaction is usually indispensable to ensure the regio-selectivity.

Here we report a new strategy for highly effective access to multi-substituted benzenes through the construction of the benzene core via a formal $[3+3]$ cycloaddition reaction (Fig. 1d). Our approach uses enals readily prepared in three steps and unsaturated ketones as the starting material and $\mathrm{N}$-heterocyclic carbene (NHC) as the organic catalyst ${ }^{12-24}$. It is a single-step reaction that affords tetra-substituted benzenes (2,4,6trisubstituted benzoate and its analogues) with high yield. In comparison, previous approaches to this class of molecules typically need seven steps with less than $10 \%$ overall yields ${ }^{25}$ (Fig. 1d). A plausible pathway of our NHC-catalyzed [3+3] cycloaddition reaction involving formal $\alpha$-, and $\gamma$-carbon activations of enal is illustrated in Fig. 2. Briefly, addition of the carbene catalyst to the aldehyde moiety of enal followed by deprotonation forms Breslow intermediate $\mathbf{I}^{26-28}$. This process is followed by oxidative transformation ${ }^{29-33}$, and former enal $\gamma-\mathrm{CH}$ deprotonation $^{33}$ leads to vinyl enolate intermediate III. Notably, similar vinyl enolate intermediate could also be accessed from ketenes $^{34}$ by Ye or esters in our laboratory ${ }^{35}$. Nucleophilic Michael-type addition of the $\gamma$-carbon of III to enone 2 affords intermediate IV bearing a NHC-bound $\alpha, \beta$-unsaturated ester

a<smiles>C=C1Cc2cc(-c3cc4c(c(-c5ccc(Br)c6c5CCOC6=O)c3)C(=O)OCC4)ccc2CC(C)=C1CC</smiles><smiles>C=C[C+]c1cc(C)c(C(=O)OC)c(Br)c1</smiles>

C<smiles>Cc1ccccc1</smiles>

d

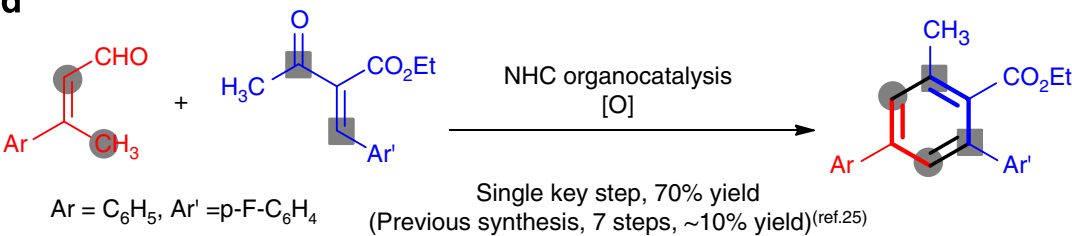

Figure 1 | Multi-substituted benzenes and their synthesis. (a) examples of natural products and bioactive synthetic compounds containing multi-substituted benzene. (b) it took about eight steps for the classical substitution methods to synthesize a 2,4,6-trisubstituted benzoate. (c) transition metal-catalyzed $\mathrm{C}-\mathrm{H}$ activation methods provides a shortcut (about five steps) for the synthesis. (d) this work: single key step reaction to afford tetra-substituted benzenes via organocatalyzed formal $[3+3]$ cycloaddtion. 


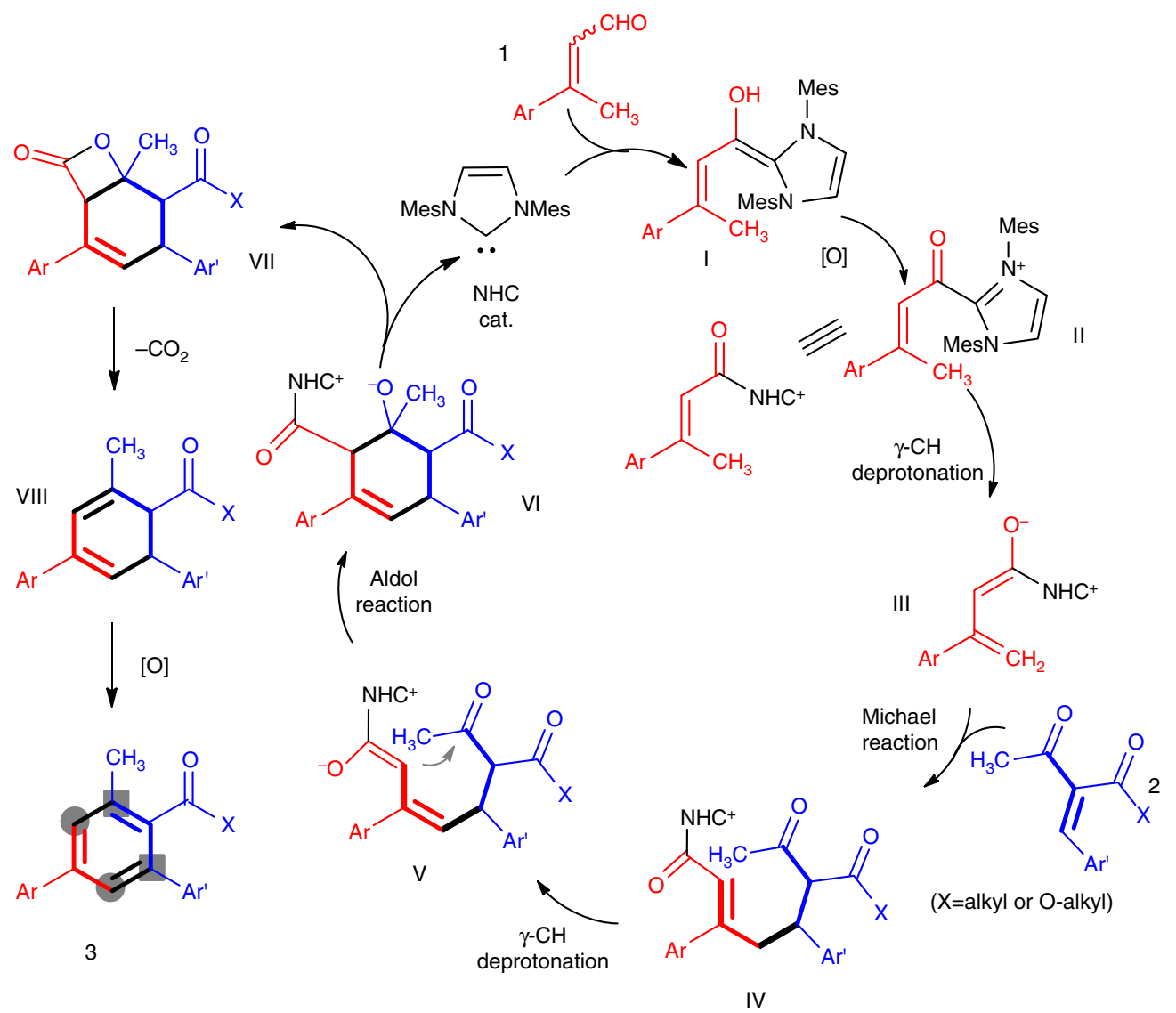

Figure 2 | Postulated pathway. Addition of carbene catalyst to aldehyde followed by oxidative transformation and $\gamma$ - $\mathrm{CH}$ deprotonation leads to intermediate III, which undergoes Michael addition to $\mathbf{2}$ and gives intermediate IV. Subsequent $\gamma$-CH deprotonation of IV lead to $\mathbf{V}$, after intramolecular adol reaction, decarboxylation and oxidation, finally gives a benzene product bearing four substituents in predictable substitution patterns. Mes, 2,4,6trimethylphenyl. Cat., catalyst.

moiety. Subsequent $\gamma$ - $\mathrm{CH}$ deprotonation of IV lead to dienolate intermediate $\mathbf{V}$ that undergoes an intramolecular aldol to form a cyclic intermediate VI. Intramolecular ester formation with the release of NHC catalyst yields a bicyclic adduct VII containing a four-membered $\beta$-lactone. Spontaneous decarboxylation ${ }^{36-39}$ and oxidation $^{40-42}$ of VII effectively affords benzene product bearing four substituents in predictable substitution patterns. Decarboxylation of $\beta$-lactone fused with a six-membered ring similar to intermediate VII is a highly effective process, as exemplified in Lupton's $[4+2]$ reaction via carbene catalysis ${ }^{39}$.

\section{Results}

Reaction optimization. We started by using enal 1a and enone $2 \mathbf{a}$ as the model substrates, in the presence of 2 equiv. quinone 4 as an oxidant ${ }^{29-33}$ and $\mathrm{Cs}_{2} \mathrm{CO}_{3}$ as a base. No formation of the proposed benzene $\mathbf{3 a}$ was observed in the absence of an NHC precatalyst (Table 1 , entry 1 ). The $N$-methyl imidazolium NHC A (ref. 43) and $N$-phenyl imidazolium B could not initiate the reaction (Table 1, entries 2-3). We then found that with $N$-Mes imidazolium C (ref. 44) as the NHC precatalyst, the proposed product 3 was formed in $88 \%$ isolated yield (Table 1, entry 4). Triazolium-based NHCs behaved similarly as the imidazolium catalysts: triazolium D (ref. 45) (with a $N$-phenyl substituent) could not catalyze the reaction; while the use of triazolium $\mathbf{E}$ (ref. 46) with a $N$-mesityl substituent could lead the formation of 3 in $47 \%$ yield (Table 1, entries 5-6). Thiazolium-based NHCs $\mathbf{F}$ (ref. 47) or G (ref. 48) could not initiate the reaction (Table 1, entries 7-8). We then evaluated the effects of solvents and bases.
Table 1 | Condition optimization for NHC-catalyzed [3 +3] benzene construction.
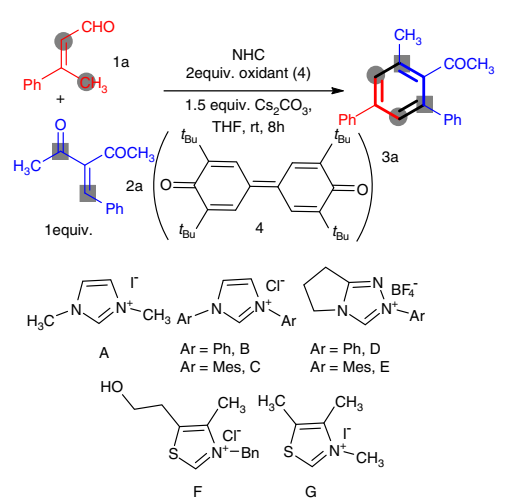

\begin{tabular}{lcc}
\hline Entry & NHC precatalyst (mol\%) & Yield (\%) \\
\hline 1 & 0 & 0 \\
2 & A $(30)$ & Trace \\
3 & B $(30)$ & Trace \\
4 & C $(30)$ & 88 \\
5 & D $(30)$ & Trace \\
6 & $\mathbf{E}(30)$ & 47 \\
7 & $\mathbf{F}(30)$ & Trace \\
8 & $\mathbf{G}(30)$ & Trace \\
9 & $\mathbf{C}(5)$ & 76 \\
\hline
\end{tabular}

$\mathrm{NHC}, \mathrm{N}$-heterocyclic carbene.

The reaction was carried out in $1.0 \mathrm{ml}$ solvent under $\mathrm{N}_{2}$. Yields of $\mathbf{3 a}$ were isolated yields after $\mathrm{SiO}_{2}$ chromatography purification. See Supplementary Table 1 for results under other conditions. 
Although the combination of tetrahydrofuran and $\mathrm{Cs}_{2} \mathrm{CO}_{3}$ was optimal, other common organic solvents (such as $\mathrm{CH}_{2} \mathrm{Cl}_{2}$, toluene, $\mathrm{CH}_{3} \mathrm{CN}$ and $\mathrm{DMF}$ ) and organic/inorganic bases (such as $\mathrm{Et}_{3} \mathrm{~N}, \mathrm{DBU},{ }^{t} \mathrm{BuOK}$ and $\mathrm{K}_{2} \mathrm{CO}_{3}$ ) could also be used (see the Supplementary Table 1). Further investigation showed that the catalyst loading of $\mathbf{C}$ could be decreased to $5 \mathrm{~mol} \%$ with acceptable $76 \%$ yield (Table 1 , entry 9 ).

Scope of enal substrates. With an acceptable reaction condition in hand (Table 1, entry 9), the scope of the reaction was evaluated. To demonstrate broader synthetic utility of this method, we chose enone $\mathbf{2} \mathbf{b}$ bearing an alkene group (amenable for further transformation) as a model enone substrate to study the generality of the enal substrates (Fig. 3, products $\mathbf{3 b} \mathbf{b} \mathbf{j}$ ). Both electron-donating (products $\mathbf{3 c}-\mathbf{d}, \mathbf{3 f}$ ) and electron-withdrawing group (products $3 \mathbf{e}, \mathbf{3 g}$ ) at the $p$ - position (products $3 \mathbf{c}-\mathbf{e}$ ) or $m$ - position (products $3 \mathbf{f}-\mathbf{g}$ ) of the $\beta$-phenyl group were welltolerated. Replacement of the $\beta$-phenyl substituent with a naphthyl (product $\mathbf{3 h}$ ) or heteroaryl unit (products $\mathbf{3 i}-\mathbf{j}$ ) had little effect on the reaction outcome. It is worth to note that $E$ - or $Z$-isomer of enal 1 gave essentially the same yields, so a mixture of $E$-/Z-enals can be directly used.

Scope of enone substrates. With aldehydes $\mathbf{1 a}$ and $\mathbf{1 b}(\mathrm{Ar}=$ 4- $\left.\mathrm{OCH}_{3}-\mathrm{C}_{6} \mathrm{H}_{4}\right)$ as model nucleophile, the scope of enones was also examined. As shown in Fig. 3 (products $3 \mathbf{k}-\mathbf{z} \mathbf{1}$ ), in nearly all

$$
\begin{aligned}
& \mathrm{R}^{1}=\text { aryl or alkenyl } \\
& \mathrm{R}^{2}=\mathrm{COR}, \mathrm{CO}_{2} \mathrm{R}, \mathrm{NO}_{2} \\
& \mathrm{R}^{3}=\text { alkyl, } \mathrm{CF}_{3}
\end{aligned}
$$$$
\text { a Examples of different enals: }\left(\mathrm{H}_{3} \mathrm{C}\right.
$$<smiles>CC(=O)c1c(C)cc(-c2ccc(P)cc2)cc1/C=C/c1ccccc1</smiles><smiles>[10BH][18F]</smiles>
OMe, $3 \mathrm{c}, 88 \%$ $\mathrm{Me}, 3 \mathrm{~d}, 72 \%$ $\mathrm{Cl}, \quad 3 \mathrm{e}, 64 \%$<smiles>COc1cc(-c2cccc(P)c2)cc(C)c1C(C)=O</smiles><smiles>CC(=O)c1c(C)cc(-c2ccc3ccccc3c2)cc1/C=C/c1ccccc1</smiles><smiles>CC(=O)c1c(C)cc(-c2ccco2)cc1/C=C/c1ccccc1</smiles><smiles>CC(=O)c1c(C)cc(-c2cccs2)cc1/C=C/c1ccccc1</smiles>

b Examples of differente nones:<smiles>[X]C(=O)c1c(C)cc(-c2ccccc2)cc1/C=C/C(=O)OCC</smiles>

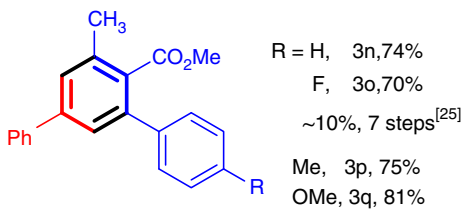<smiles>CC(=O)c1c(C)cc(-c2ccccc2)cc1-c1ccc(Cl)cc1</smiles><smiles>COC(=O)c1c(P)cc(-c2ccccc2)cc1/C=C/c1ccccc1</smiles>

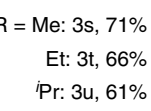<smiles>COc1ccc(-c2cc(C)c(C(C)=O)c(-c3ccc(Cl)cc3)c2)cc1</smiles><smiles>CCc1cc(-c2ccccc2)cc(-c2ccccc2)c1C(C)=O</smiles><smiles>[R]c1c(C)cc(-c2ccc(OC)cc2)cc1/C=C/c1ccccc1</smiles>

$3 w, 76 \%$

$$
\mathrm{NO}_{2}, 3 y, 52 \%
$$<smiles>COc1ccc(-c2cc(-c3ccccc3)c(C(=O)O)c(C(F)(F)F)c2)cc1</smiles>

$\mathrm{Ph}, 3 \mathrm{z} 1,54 \%$

Figure 3 | Substrate scope. (a) Examples of different enals: study of enal substrate generality with ketone $\mathbf{2 b}$ as a model enone substrate. (b) Examples of different enones: study of enones scope with aldehydes $\mathbf{1 a}\left(\mathrm{Ar}=\mathrm{C}_{6} \mathrm{H}_{5}\right)$ and $\mathbf{1 b}\left(\mathrm{Ar}=4-\mathrm{OCH}_{3}-\mathrm{C}_{6} \mathrm{H}_{4}\right)$ as model nucleophile. Ph, phenyl; Me, methyl; Et, ethyl. 

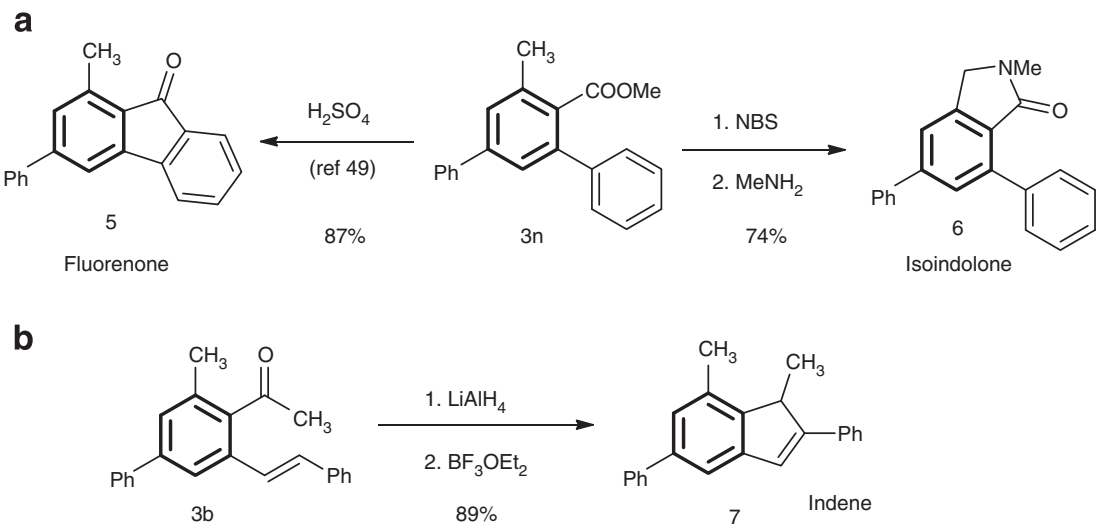

Figure 4 | Synthetic applicability. (a) 3n can be transfomed to fluorenone $\mathbf{5}$ or isoindolone $\mathbf{6}$ via straightforward processes. (b) 3b could be transformed to indene $\mathbf{7}$ via reduction followed by Lewis acid-mediated cyclization. NBS, N-bromosuccinimide.

cases, the reaction proceeded smoothly at room temperature to give polysubstituted benzenes in moderate to good yields. Notably, the E-/Z-configuration of enone 2 did not affect the reaction outcomes either (for example, see product $3 \mathbf{k}$ ), which greatly simplify substrate preparation process. Both electron-rich (products $\mathbf{3} \mathbf{p}-\mathbf{q}$ ) or electron-deficient (products $\mathbf{3 o}$ and $3 \mathbf{r}$ ) aromatic groups, as well as vinyl groups (products $\mathbf{3 k}-\mathbf{m}$ ) were all tolerated in the $\beta$-substituent $\left(R^{2}\right)$ of the enone substrates. $\alpha$-Substituent $\left(\mathrm{R}^{3}\right)$ of the enone substrates can be electron-deficient units such as $\operatorname{acyl}(\mathbf{3 m}, \mathbf{3 r}, \mathbf{3 v}-\mathbf{3 w})$, ester (3k-1, $\mathbf{3 n}-\mathbf{q}$ ) or nitro (3y) groups. Substituent in the carbonyl group of enones $2\left(\mathrm{R}^{4}\right)$ can be a different alkyl group including methyl $(3 \mathbf{k}-\mathbf{q}, 3 \mathbf{r}-\mathbf{s})$, ethyl (3t and $\mathbf{3 w}$ ), isopropyl (3u) or trifluoromethyl $(\mathbf{3 z}-\mathbf{z 1})$ group.

It is important to note that these polysubsituted benzene molecules were difficult to prepare previously. For example, previous method for the synthesis of benzoate 30 required seven steps with less than $10 \%$ overall yields ${ }^{25}$; previous synthesis of $3 \mathbf{p}$ and $3 \mathbf{q}$ needed a three-step reaction with 35 and $39 \%$ overall yield $^{49}$, respectively. Our method also provides effective access to aromatic molecules with trifluoromethyl $\left(\mathrm{CF}_{3}\right)$ substituent. In organic synthesis, regioselective $\mathrm{C}-\mathrm{H}$ trifluoromethylation ${ }^{50,51}$ or methylation $^{52-54}$ of aryl molecules still remains challenging despite the rapid development in recent years.

Product transformation. We next demonstrated effective transformation of our catalytic reaction products to bicyclic and multicylic aromatic molecules that are found as a key scaffold in natural products and functional synthetic molecules. For example, the multisubsituted benzene adduct $\mathbf{3 b}$ could be transformed to indene 7 (ref. 55) via reduction followed by Lewis acidmediated cyclization; 2,4,6-trisubstituted benzoate $3 \mathbf{n}$ can be transformed to fluorenone 5 (refs 56,49) or isoindolone 6 (ref. 57) via straightforward processes (Fig. 4).

\section{Discussion}

In summary, we have developed a NHC organocatalytic strategy for the formal $[3+3]$ construction of multi-substituted benzenes. Our method directly employs commercially available or easily accessible enals and enones to construct benzene framework with excellent regioselectivities, offering useful insights into the design of concise synthetic strategies for complex molecules. Further studies regarding reaction mechanisms, synthetic applications and axial chirality controls (for the formation of substituted benzene products) are under progress in our laboratory.

\section{Methods}

Materials. For ${ }^{1} \mathrm{H},{ }^{13} \mathrm{C}$ and ${ }^{19} \mathrm{~F}$ NMR spectra of compounds in this manuscript, see Supplementary Figs 1-32. For details of the synthetic procedures, see Supplementary Methods.

Synthesis of 3. Under $\mathrm{N}_{2}$ atmosphere, a solution of enal $(0.1 \mathrm{mmol})$, enone ( $0.1 \mathrm{mmol})$, oxidant $4(82 \mathrm{mg}, 0.2 \mathrm{mmol}), \mathrm{Cs}_{2} \mathrm{CO}_{3}(48.7 \mathrm{mmg}, 0.15 \mathrm{mmol})$ and imidazolium C $(1.7 \mathrm{mg}, 0.005 \mathrm{mmol})$ in $1.0 \mathrm{ml}$ tetrahydrofuran was stirred at room temperature for $8 \mathrm{~h}$. The mixture was concentrated under reduced pressure and purified by silica gel column chromatography to afford the corresponding product 3.

\section{References}

1. Mahmood, T., Ahmed, E. \& Malik, A. Structure determination of salvadorin, a novel dimeric dihydroisocoumarin from salvadora oleoides, by NMR spectroscopy. Magn. Reson. Chem. 43, 670-672 (2005).

2. Stokker, G. E., Alberts, A. W., Gilfillan, J. L., Huff, J. W. \& Smith, R. L. 3-hydroxy-3- methylglutaryl-coenzyme A reductase inhibitors. 5. 6-(Fluoren-9yl)-and 6(Fluoren-9-ylidenyl)-3, 5-dihydroxyhexanoic acids and their lactone derivatives. J. Med. Chem. 29, 852-855 (1986).

3. Ortar, G. et al. 3-ylidenephthalides as a new class of transient receptor potential channel TRPA1 and TRPM8 modulators. Bioorg. Med. Chem. Lett. 23, 5614-5618 (2013).

4. Robison, M. M. \& Robison, B. L. 2,4,6-tribromobenzoic acid. Org. Synth. 36, 94-97 (1956).

5. Cossy, J. \& Arseniyadis, S. Modern Tools for the Synthesis of Complex Bioactive. Ch. 1, 1-32 (Wiley, 2012).

6. Wencel-Delord, J., Dröge, T., Liu, F. \& Glorius, F. Towards mild metalcatalyzed C-H bond activation. Chem. Soc. Rev. 40, 4740-4761 (2011).

7. Arockiam, P. B., Bruneau, C. \& Dixneuf, P. H. Ruthenium (II)-catalyzed C-H bond activation and functionalization. Chem. Rev. 112, 5879-5918 (2012).

8. Engle, K. M., Mei, T.-S., Wasa, M. \& Yu, J.-Q. Weak coordination as a powerful means for developing broadly useful C-H functionalization reactions. Acc. Chem. Res. 45, 788-802 (2012).

9. Reppe, W., Schlichting, O., Klager, K. \& Toepel, T. Cyclisierende polymerisation von acetylen I über cyclooctatetraen. Justus Liebigs Ann. Chem 560, 1-92 (1948).

10. Domínguez, G. \& Pérez-Castells, J. Recent advances in $[2+2+2]$ cycloaddtion reactions. Chem. Soc. Rev. 40, 3430-3444 (2011).

11. Hoye, T. R., Baire, B., Niu, D., Willoughby, P. H. \& Woods, B. P. The hexadehydro-Diels-Alder reaction. Nature 490, 208-212 (2012).

12. Enders, D. \& Balensiefer, T. Nucleophilic carbenes in asymmetric organocatalysis. Acc. Chem. Res. 37, 534-541 (2004).

13. Zeitler, K. Extending mechanistic routes in heterazolium catalysis-promising concepts for versatile synthetic methods. Angew. Chem. Int. Ed. 44, 7506-7510 (2005).

14. Marion, N., Diez-Gonzalez, S. \& Nolan, S. P. N-heterocyclic carbenes as organocatalysts. Angew. Chem. Int. Ed. 46, 2988-3000 (2007).

15. Nair, V., Vellalath, S. \& Babu, B. P. Recent advances in carbon-carbon bond-forming reactions involving homoenolates generated by NHC catalysis. Chem. Soc. Rev. 37, 2691-2698 (2008).

16. Vora, H. U. \& Rovis, T. Asymmetric N-heterocyclic Carbene (NHC) catalyzed acyl anion reactions. Aldrichim. Acta 44, 3-11 (2011). 
17. Douglas, J., Churchill, G. \& Smith, A. D. NHCs in asymmetric organocatalysis: recent advances in azolium enolate generation and reactivity. Synthesis. (Mass). 44, 2295-2309 (2012).

18. Phillips, E. M., Chan, A. \& Scheidt, K. A. Discovering new reactions with N-heterocyclic carbene catalysis. Aldrichim. Acta 42, 55-66 (2009).

19. Izquierdo, J., Hutson, G. E., Cohen, D. T. \& Scheidt, K. A. A continuum of progress: applications of $\mathrm{N}$-hetereocyclic carbene catalysis in total synthesis. Angew. Chem. Int. Ed. 51, 11686-11698 (2012).

20. Ryan, S. J., Candish, L. \& Lupton, D. W. Acyl anion free N-heterocyclic carbene organocatalysis. Chem. Soc. Rev. 42, 4906-4917 (2013).

21. Chiang, P.-C. \& Bode, J. W. N-mesityl substituted chiral triazolium salts: opening a new world of N-heterocyclic carbene catalysis. TCI Mail 149, 2-17 (2011).

22. Bode, J. W. Carbene catalysis: an internal affair. Nat. Chem. 5, 813-815 (2013).

23. Bugaut, X. \& Glorius, F. Organocatalytic umpolung: $N$-heterocyclic carbenes and beyond. Chem. Soc. Rev. 41, 3511-3522 (2012).

24. Hopkinson, M. N., Richter, C., Schedler, M. \& Glorius, F. An overview of N-heterocyclic carbenes. Nature 510, 485-496 (2014).

25. Robl, J. A. A new and versatile route for the synthesis of highly substituted benzenoids. Tetrahedron Lett. 31, 3421-3424 (1990).

26. Teles, J. H. et al. Benzoin-type condensations of formaldehyde catalyzed by stable carbenes. Helv. Chim. Acta 79, 61-83 (1996).

27. Miyashita, A. et al. Synthesis and reactivities of 1,3-dimentyl-2- $(\alpha-$ hydroxybenzyl)imidazolium and 1,3-dimentyl-2-( $\alpha$ - hydroxybenzyl) benzimidazolium iodides. Heterocyles 44, 417-426 (1997).

28. Collett, C. J. et al. Mechanistic insights into the trazolylidene-catalysed Stetter and benzoin reactions: role of the $N$-aryl substituent. Chem. Sci. 4, 1514-1522 (2013).

29. Sarkar, S. D. \& Studer, A. NHC-catalyzed michael addition to $\alpha, \beta$-unsaturated aldehydes by redox activation. Angew. Chem. Int. Ed. 49, 9266-9269 (2010).

30. Rong, Z.-Q., Jia, M.-Q. \& You, S.-L. Enantioselective N-heterocyclic carbenecatalyzed michael addition to $\alpha, \beta$-unsaturated aldehydes by redox oxidation. Org. Lett. 13, 4080-4083 (2011).

31. Zhao, X., Ruhl, K. E. \& Rovis, T. N-heterocyclic-carbene-catalyzed asymmetric oxidative hetero-Diels- Alder reactions with simple aliphatic aldehydes. Angew. Chem. Int. Ed. 51, 12330-12333 (2012).

32. Kravina, A. G., Mahatthananchai, J. \& Bode, J. W. Enantioselective, NHCcatalyzed annulations of trisubstituted enals and cyclic $N$-sulfonylimines via $\alpha, \beta$-unsaturated acyl azoliums. Angew. Chem. Int. Ed. 51, 9433-9436 (2012).

33. Mo, J., Chen, X. \& Chi, Y. R. Oxidative $\gamma$-addition of enals to trifuoromethyl ketones: enantioselectivity control via Lewis acid/ $N$-heterocyclic carbene cooperative catalysis. J. Am. Chem. Soc. 134, 8810-8813 (2012).

34. Shen, L.-T., Shao, P.-L. \& Ye, S. N-heterocyclic carbene-catalyzed cyclization of unsaturated acyl chlorides and ketones. Adv. Synth. Catal. 353, 1943-1948 (2011).

35. Xu, J., Jin, Z. \& Chi, Y. R. Organocatalytic enantioselective $\gamma$-aminoalkylation of unsaturated ester: access to pipecolic acid derivatives. Org. Lett. 15, 5028-5031 (2013).

36. Nair, V., Vellalath, S., Poonoth, M. \& Suresh, E. N-heterocyclic carbenecatalyzed reaction of chalcones and enals via homoenolate: an efficient synthesis of 1,4,5-Trisubstituted cyclopentenes. J. Am. Chem. Soc. 128, 8736-8737 (2006).

37. Chiang, P.-C., Rommel, M. \& Bode, J. W. $\alpha^{\prime}$-hydroxyenones as mechanistic probes and scope-expanding surrogates for $\alpha, \beta$-Unsaturated aldehydes in $N$ heterocyclic carbene- catalyzed reactions. J. Am. Chem. Soc. 131, 8714-8718 (2009).

38. Cardinal-David, B., Raup, D. E. A. \& Scheidt, K. A. Cooperative N-heterocyclic carbene/Lewis acid catalysis for highly stereoselective annulation reactions with homoenolates. J. Am. Chem. Soc. 132, 5345-5347 (2010).

39. Ryan, S. J., Candish, L. \& Lupton, D. W. N-heterocyclic carbene-catalyzed $(4+2)$ cycloaddtion/ decarboxylation of silyl dienol ethers with $\alpha, \beta$ unsaturated acid fluorides. J. Am. Chem. Soc. 133, 4694-4697 (2011)

40. Izawa, Y., Pun, D. \& Stahl, S. S. Palladium-catalyzed aerobic dehydrogeneation of substituted cyclohexanones to phenols. Science 333, 209-213 (2011)

41. Girard, S. A. et al. Pd-catalyzed synthesis of aryl amines via oxidative aromatization of cyclic ketones and amines with molecular oxygen. Org. Lett. 14, 5606-5609 (2012).

42. van Otterlo, W. A. \& de Koning, C. B. Metathesis in the synthesis of aromatic compounds. Chem. Rev. 109, 3743-3782 (2009).
43. Ye, W., Cai, G., Zhuang, Z., Jia, X. \& Zhai, H. One-step assembly of functionalized $\gamma$-butyrolactones from benzoins or benzaldehydes via an $N$ heterocyclic carbene-mediated tandem reaction. Org. Lett. 7, 3769-3771 (2005).

44. Burstein, C. \& Glorius, F. Organocatalyzed conjugate umpolung of $\alpha, \beta$ Unsaturated aldehydes for the synthesis of $\gamma$-butyrolactones. Angew. Chem. Int. Ed. 43, 6205-6208 (2004).

45. Reynolds, N. T., de Alaniz, J. R. \& Rovis, T. Conversion of $\alpha$-haloaldehydes into acylating agents by and internal redox reaction catalyzed by nucleophilic carbenes. J. Am. Chem. Soc. 126, 9518-9519 (2004).

46. Bode, J. W. \& Sohn, S. S. N-heterocyclic carbene-catalyzed redox amidations of $\alpha$-functionalized aldehydes with amines. J. Am. Chem. Soc. 129, 13798-13799 (2007).

47. Stetter, H. \& Kulmann, H. Acyloin condensation by thiazolium ion catalysis: butyroin. Org. Synth. 62, 170-174 (1984).

48. Castells, J., Llitjos, H. \& Moreno_Manas, M. Nitrobenzene aldehyde oxidations catalyzed by the conjugate bases of thiazolium ions. Tetrahedron Lett. 2, 205-206 (1977).

49. Reim, S., Lau, M. \& Langer, P. Synthesis of fluorenones based on a ' $[3+3]$ cyclization/Suzuki cross-coupling/Friedel-Crafts acylation' strategy. Tetrahedron Lett. 47, 6903-6905 (2006).

50. Nagib, D. A. \& Macmillan, D. W. C. Trifluoromethylation of arenes and heteroarenes by means of photoredox catalysis. Nature 480, 224-228 (2011).

51. Fujiwara, Y. et al. Practical and innate carbon-hydrogen functionalization of heterocycles. Nature 492, 96-99 (2012).

52. Schönherr, H. \& Cernak, T. Profound methyl effects in drug discovery and a call for new C-H methylation reactions. Angew. Chem. Int. Ed. 52, 12256-12267 (2013).

53. Giri, R. et al. Palladium-Catalyzed Methylation and arylation of $\mathrm{sp}^{2}$ and $\mathrm{sp}^{3}$ C-H bonds in simple carboxylid acids. J. Am. Chem. Soc. 129, 3510-3511 (2007).

54. Rosen, B. R. et al. C-H functionalization logic enables synthesis of (+)Hongoquercin A and related compounds. Angew. Chem. Int. Ed. 52, 7317-7320 (2013).

55. Antonio, D. S. et al. Preparation and pharmacological chracterization of trans-2-amino-5(6)-fluoro- 6(5)-hydroxy-1-phenyl-2,3-dihydro-1H-indenes as $\mathrm{D}_{2}$-like Dopamine receptor agonists. J. Med. Chem. 48, 2646-2654 (2005).

56. Perry, P. J. et al. 2,7-Disubstituted amdofluorenone derivatives as inhibitors of human telomerase. J. Med. Chem. 42, 2679-2684 (1999).

57. Lawson, E. C. et al. Nonpeptide Urotesin-II receptor antagonist: a new ligand class based on piperazino-phthalimide and piperazino-isoindolinone subunits. J. Med. Chem. 52, 7432-7445 (2009).

\section{Acknowledgements}

We acknowledge support by the Singapore National Research Foundation (NRF), the Singapore Economic Development Board (EDB), GlaxoSmithKline (GSK) and the Nanyang Technological University (NTU); China's National Key programme for Basic Research (No. 2010CB 126105), the National Natural Science Foundation of China (No. 21132003) and the Guizhou University (China).

\section{Author contributions}

T.Z. conducted most of the experiments; P.Z. and C.M. prepared substrates for the reaction scope evaluation; S.Y., B.-A.S. and Y.R.C. conceptualized and directed the project, and drafted the manuscript with the assistance from all co-authors. All authors contributed to discussions.

\section{Additional information}

Supplementary Information accompanies this paper at http://www.nature.com/ naturecommunications

Competing financial interests: The authors declare no competing financial interests.

Reprints and permission information is available online at http://npg.nature.com/ reprintsandpermissions/

How to cite this article: Zhu, T. et al. Benzene construction via organocatalytic forma [3+3] cycloaddition reaction. Nat. Commun. 5:5027 doi: 10.1038/ncomms6027 (2014). 